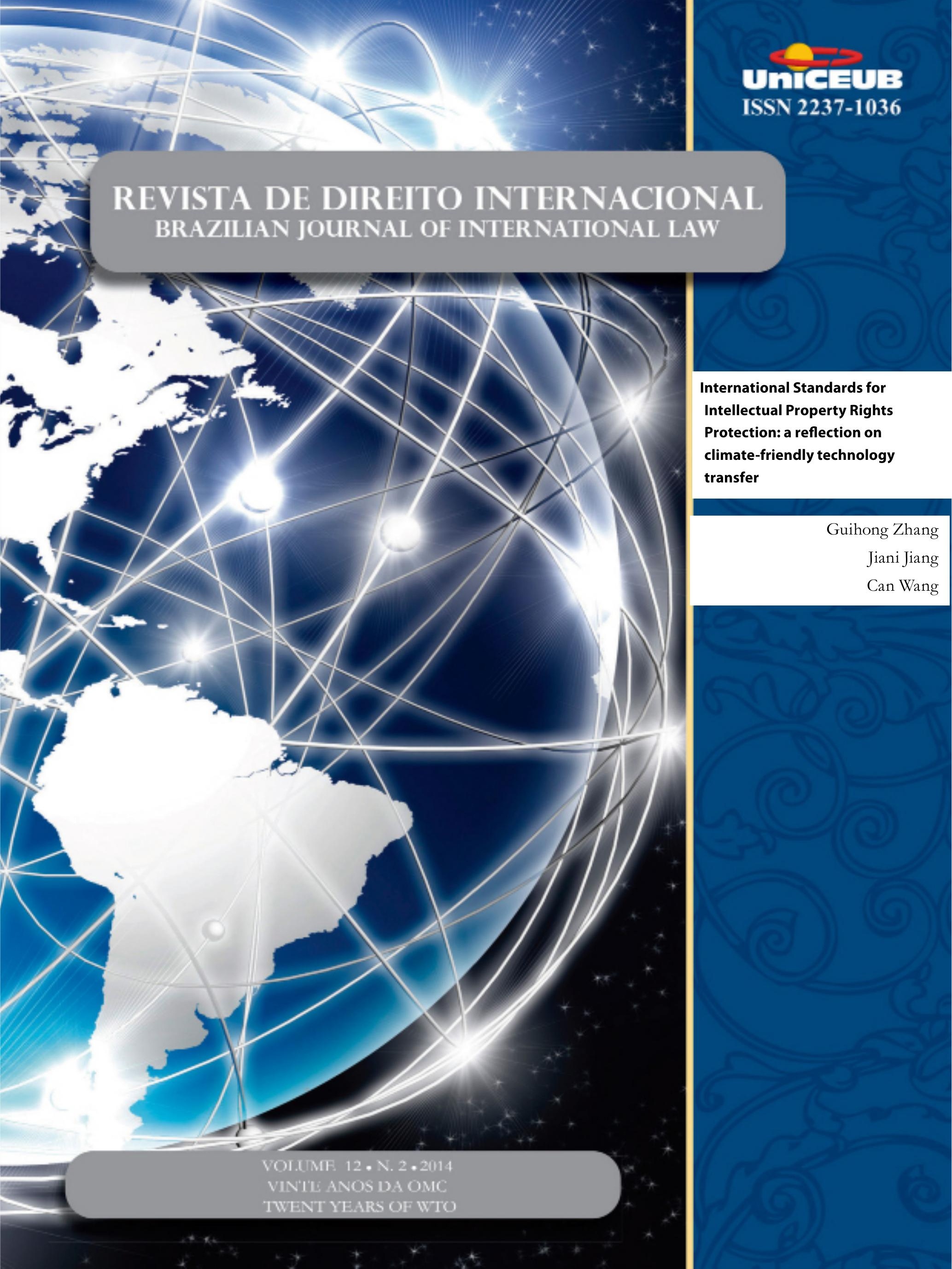


I. Crônicas

1. Crônicas da atualidade do Direito Internacional ......................................................16

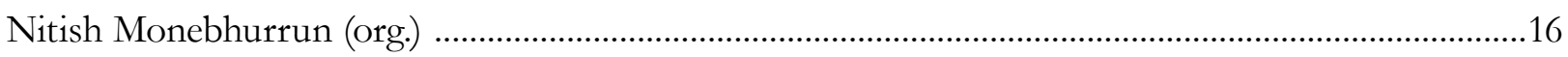

2.Decisões da Corte Internacional de Justiça e do Tribunal Internacional Sobre o Direito do Mar

Nitish Monebhurrun

José Eduardo Siqueira

3. Crônicas do direito internacional dos inVestimentos

Nitish Monebhurrun

\section{Os Vinte Anos dA OMC}

EXPORT CONTROLS AS INDUSTRIAL POLICY ON NATURAL RESOURCES: REGULATORY LIMITATIONS ON CHINA - RAW MATERIALS AND CHINA - RARE EARTHS CASES.

Gustavo Ferreira Ribeiro

O problema da espionagem econômica internacional: Seria a Organização Mundial do CoMÉRCIO O FORO ADEQUADO PARA SUA APRECIAÇÃO?

Humberto A.Vasconcelos Lima

Naiana Magrini Rodrigues Cunha

International Standards for Intellectual Property Rights Protection: a reflection on CLIMATE-FRIENDLY TECHNOLOGY TRANSFER.

Guihong Zhang

Jiani Jiang

Can Wang

Os vinte anos da OMC, suas conquistas e desafios: uma análise do Brasil e o Sistema de SoLUÇõES DE CONTROvÉRsias

Etiene M. Bosco Breviglieri

Luciano Meneguetti Pereira

A relação entre os tratados multilaterais ambientais e os acordos da OMC: é possível CONCILIAR O CONFLITO?

Fabio Costa Morosini,

Luisa Zuardi Niencheski 
Um desafio na Organização Mundial do Comércio: viabilidade de um acordo plurilateral SOBRE ENERGIA.

Matheus Linck Bassani

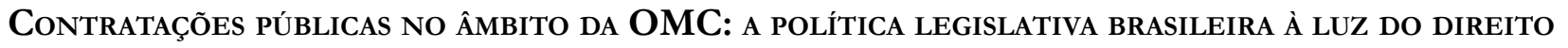
AO DESENVOLVIMENTO

André Jansen do Nascimento

Governança global e a Organização Mundial do Comércio: desafios impostos pelo novo MANDATO DE DESENVOLVIMENTO

Letícia de Souza Daibert

Ana Luísa Soares Peres

Vinte Anos de Crise para a África? Poder, Assimetrias e a Abordagem liberal da OMC.....239 Igor Abdalla Medina de Souza

Os MECANISMOS DE INDUÇÃo AO CUMPRIMENTO NO ÂMBITO DA OMC 258

Fernando Lopes Ferraz Elias

A promoção de accountability na Organização Mundial do Comércio: uma análise horiZONTAL E VERTICAL.

Celso Henrique Cadete de Figueiredo

LA OMC Y EL PROCESO DE GLOBALIZACION DE LA REGULACIÓN ALIMENTARIA

Maria Eugenia Marichal

O ACORDO GATS E SUA APLICAÇÃO AOS SERVIÇOS DO COMÉRCIO ELETRÔNICO

Gleisse Ribeiro Alves

A OMC E O REgIONALISMo do SÉCULO XXI: ESTRATÉGIA DE IMPOSIÇÃo DE MODELOS NORMATIVOs? .. 337 Camilla Capucio

A organização mundial do comércio e a China: direito de Propriedade e Propriedade inteLECTUAL NO PAÍS

Dos contenciosos NA OMC COM ENFOQue EM RESTRições Às EXPORTAÇõEs DA CHINA 363 Marco Antônio Alcântara Nascimento 
Alice Rocha da Silva

\section{Outros Temas}

Derechos Humanos EN LA REALIDAD ACTUAL: LA GLOBALIZACión Y El MUlTiCulturalismo

David Falcão

IMUNIDAdE DE JURISDIÇÃo do EsTAdo E REPARAÇÃo CIVIL PELA PRÁtiCa DE TORTURA: O CASO ZaHRA

KAZEMI v. REPÚBLICA IsLÂMICA do Irã.

Patrícia Maria Lara Abreu

Rodrigo Otávio Bastos Silva Raposo

INTERREGIONAL ORgANIZATIONS (IROS) IN EUROPE: NEW SUBJECTS OF CONTEMPORARY INTERNATIONAL LAW? .

Davorin Lapas

A CONEXão entre os direitos humanos E A CORRUPÇÃo.

Gabriela Alves Mendes Vieira

Marcelo Dias Varella

GRUPO DE SOCIEDADES: INSTRUMENTO JURÍDICO DE ORGANIZAÇÃo DA EMPRESA PLURISSOCIETÁRIA......495

Daniel Amin Ferraz 


\title{
International Standards for Intellectual Property Rights Protection: a reflection on climate-friendly technology transfer*
}

\author{
Guihong Zhang ${ }^{* *}$ \\ Jiani Jiang ${ }^{* * *}$ \\ Can Wang ${ }^{* * * *}$
}

\begin{abstract}
An unsettled debate exists with regard to the role of intellectual property (IP) rights in international climate negotiation. This debate is based on premise that the international TRIPS Agreement set out minimum standards of protection, which presumably allow for unlimited extra protection. This study aims to address the question of whether a premise for minimum protection standards exists in the international IP system combined with climate-friendly technology transfer. First, the basic question of why international IP standards generate an impact on climate-friendly technology transfer is clarified. Second, three levels of arguments are applied to question this premise and examine the rationality of minimum protection standards. The three arguments are as follows: (1) Has TRIPS Agreement 1.1 provided unlimited minimal standards for IPR protection? (2) Is there no conflict between TRIPS Agreement-PLUS and the TRIPS Agreement? (3) How about the WTO dispute settlement panel report about this problem? The finding is that the dominant default policy, the IP protection standard, is the only minimum requirement in the case of uncertainty in legal provisions and practices. Therefore, the negative effects on the transfer of climate-friendly technology increase in terms of using flexible provision to promote import technologies. Third, this paper introduces China's current Patent Law and its practice in response to climate-friendly technology transfer. Lastly, this paper provides suggestions with regard to the need for comprehensive and explicit protection standards in the context of climatefriendly technology transfer.
\end{abstract}

Keywords: Climate-friendly technology. Minimum protection standards. International intellectual property rights. Developing countries. China. TRIPS Agreement. TRIPS-PLUS. DSB. Ceiling.

Environment, Tsinghua University, Areas of Specialization: Climate change policy and economics. Email: canwang@tsinghua.edu.cn. This research is funded by "Key Projects in the National Science \& Technology Pillar Program during the Twelfth Five-year Plan Period"(NO. 2012BAC20B04), the National Natural Science Foundation of China (No.71273153), and the China Scholarship Council (CSC) (NO. 201306040082).

\section{Introduction}

Climate-friendly technology requires high input and involves high risk and thus entails the establishment of a mechanism that encourages technological innovation and transfer. The patent system for climate-friendly technology is precisely built to realize this purpose. The patent system for climate-friendly technology aims to create, promote, and protect climate-friendly technology and facilitate its application. How to improve the patent system to facilitate climatefriendly technology innovation and transfer in the context of the depletion of petrochemical resources and global warming is an urgent problem. As pointed out by an ICTSD-EPO-UNEP report, after the Kyoto Protocol was passed in 1997, the number of patent applications in clean energy technology increases at an annual 
rate of approximately $20 \%$, which already exceeds that in the field of fossil fuel and nuclear energy. This phenomenon indicates that in the fight against climate change, IP legislation can definitely exert influence on climate-friendly technology innovation and transfer. Nonetheless, an unsettled debate exists regarding the role of the IP system in the development and transfer of climate-friendly technologies under the United Nations Framework Convention on Climate Change (UNFCCC) negotiation. In UNFCCC, developing parties contend that IPR impedes the diffusion of climate-friendly technologies and support evolutionary changes in the current international IP system to address climate change. ${ }^{2}$ Developed countries insist that IP promotes technology development and transfer and support an absolutely free market for climatefriendly technology transfer. They attempt to avoid references to IPR under UNFCCC. ${ }^{3}$

A recent stream of studies have addressed the role of IP in climate-friendly technology transfer. Briefly, three views exist with regard to the role of IP. In most cases, proponents of strong IP argue that patents foster climate-friendly technology development and transfer based on basic data analysis. They insist that a strong IP regime can guarantee sustained motivation for developed countries to invest in developing countries (BRANSTETTER, 2006; COPENHAGEN ECONOMICS, 2009; HOEKMAN, 2004; PUGATCH, 2010). Opponents of this view argue that the IP regime enhances many IP holders' paid-license rights but ignores the high price of the transfer. Thus, IP holders possess core technologies but are unwilling to transfer them to developing countries (ERI, 2009; LEWIS, 2006; MASKUS et al., 2005; WATAL, 1998). Other analysts observe that IP is not the only factor that impedes climate-friendly technology transfer

1 nited Nations Environment Programme (UNEP) Economics and Trade Branch, European Patent Office (EPO), International Centre for Trade and Sustainable Development (ICTSD), UNEP E P O. ICTSD. Patents and Clean Energy: Bridging the Gap Between Evidence and Policy: Final Report. Geneva, 2010. Available at:

$<$ http://www.epo.org/clean-energy $>$.

2 WN (Third Word Network), UNFCCC technology committee debates IPR issue, 2013. Available at:

<http://www.twnside.org.sg/title2/climate/info.service/2013/ climate130705.htm>.

3 CIED (The Coalition for Innovation, Employment and Development), Joint Resolution of BUSINESSEUROPE, IIPPF and the Global Intellectual Property Center on Climate Change, Technology, and Intellectual Property Rights, 2009. Available at:

<http://www.thecied.org/files / $2010 / 10 /$ FinalJointGreenTechnologiesClimateChangeStatementSept2809.pdf>.
(BARTON, 2007; OCKWELL, 2007; UNEPEPO-ICTSD, 2010). Although IP is a real challenge in climate-friendly technology transfer, it has not been formally recognized by UNFCCC despite the controversy. However, no firm evidence exists on how IP affects the diffusion of climate technologies. These studies show that IP is closely related to climate-friendly technology transfer and offers empirical analyses to clarify the role of IP in climate-friendly technology transfer. Nevertheless, literature has provided no coherent conclusion with regard to the effect of IP on climate-friendly technology because national policies make it difficult to determine the role of IP. Moreover, a few studies have explored the reason a controversy continues to exist between IP and climatefriendly technology transfer from the perspective of international laws.

Generally, in the field of international IP legislation, the IP system is believed to have been established based on minimum protection standards; no upper limit was set. This lack of upper limit serves as a legitimate basis for raising the standards of IP in signing bilateral or regional trade agreements and profoundly affects the judgment of the dispute settlement body (DSB). However, excessively high IP standards nullify the flexible clauses on the promotion of public interests set in the international IP system. With regard to actions that tackle climate change, developing countries propose refining such flexible clauses for climate-friendly technologies to become more easily transferrable. Numerous proposals have been introduced to the current international climate negotiation on technology to improve or establish a new international IP system that accommodates the transfer of climate-friendly technologies based on flexible clauses. ${ }^{4}$ Meanwhile, in the World Trade Organization (WTO) forum, the Doha Ministerial Conference agreed to establish a working group to examine the relationship between trade and technology transfer and possible recommendations for steps that may be implemented within the WTO mandate to increase the flows of technology to developing countries. The WTO's Trade-Related Aspects of Intellectual

4 In Cancun climate negotiation, Bolivia, which is one of the strongest opponents of the injustices derived from the TRIPS Agreement, insisted on weakening the IP system as a prerequisite to any climate deal. India issued a proposal for the inclusion of supplementary agenda items in the provisional agenda of COP 17 , including IP-related items, such as the treatment and delivery of climate technologies and their IPRs as a public good. 
Property (TRIPS Agreement) Council, in its first meeting for 2014, discussed the topic "Contribution of intellectual property (IP) to facilitate the transfer of environmentally rational technology." However, so far, limited advancement toward tackling climate change has been achieved. International efforts to promote climate-friendly technology innovation and transfer have not been able to transform into integrated forces because of the unresolved controversy between IP and technology transfer.

From the perspective of international laws, the essence of IP debates mainly arises from the conflicting opinions of all parties with respect to the relationship between IP level and IP protection standards. Developed countries contend that enhancing IP will facilitate technology innovation and transfer. Hence, current standards should specify only the minimum requirements and not the ceiling. By contrast, developing countries argue that enhancing IP does not necessarily facilitate technology innovation and transfer. Thus, existing protection standards should incorporate both the minimum and maximum requirements. Obviously, international IP agreements under the framework of the World Intellectual Property Organization (WIPO) and the TRIPS Agreement under WTO were set up based on the hypothesis that only minimum protection standards exist in the international IP system. ${ }^{5}$ Hitherto, TRIPS Agreement-Plus as an additional protection standard has been introduced in bilateral and regional trade agreements that involve or are dominated by developed countries. Such requirement imposes further restriction on the applicable range of the flexible clauses of the TRIPS Agreement. Thus, developing countries are likely to face a legislation challenge in terms of facilitating the transfer of climate-friendly technologies by taking advantage of the flexible clauses of the TRIPS Agreement.

As a major emitter of $\mathrm{CO}_{2}$, China has a strong demand for climate-friendly technology. China is also facing issues such as deficiency in independent research and development of climate-friendly technology and serious defects in climate-friendly technology patent transfer. Many reasons cause these problems. Such reasons include inadequate investment in research and development, inadequate infrastructures, and weak green patent consciousness. However, China must still

5 RUSE-KHAN, H. G. Time for a paradigm shift: exploring maximum standards in international intellectual property protection, 1. Trade L. \& Dev. 56, 2009. follow the above inherent assumptions ("minimum protection standards") as the starting point in establishing patent laws. These assumptions might urge the nation to increase IP protection standards while providing minimal emphasis on self-national conditions.

With these issues in mind, this paper focuses on several questions. First, why do international IP protection standards generate an impact on climatefriendly technology transfer? Second, is it true that only minimum protection standards are established by the existing international IP system? Third, what is the impact of minimum protection standards on China's climate-friendly technology patent legislation practices? Lastly, this paper provides two levels of alternative suggestions for perfecting IP legislation to enhance climate-friendly technology innovation and transfer.

\section{Transfer of climate-friendly technologies and minimum protection standards for IP}

\section{A. Definition of climate-friendly technologies}

The reform, transfer, and application of climatefriendly technology are the premises to realize the ultimate goal of climate change response described in Article 2 of UNFCCC. Article 2 of UNFCCC states the following:

The ultimate objective of this Convention and any related legal instruments that the Conference of the Parties may adopt is to achieve, in accordance with the relevant provisions of the Convention, stabilization of greenhouse gas concentrations in the atmosphere at a level that would prevent dangerous anthropogenic interference with the climate system. Such a level should be achieved within a time frame sufficient to allow ecosystems to adapt naturally to climate change, to ensure that food production is not threatened and to enable economic development to proceed in a sustainable manner.

Climate-friendly technologies, including solar photovoltaic and wind power generation technologies, are also known as environmentally sound, clean energy, and new energy technologies. The improvement of energy utilization efficiency and the development of climate-friendly technology create a bright prospect of $\mathrm{CO}_{2}$ emission reduction. These technologies can 
effectively lower the consumption of materials and energy and mitigate the negative impact on the environment. The important document Agenda 21 issued by United Nations Conference on Sustainable Development in 1992 provides a clear definition of climate-friendly technology; its Article 34.1 states that

Environmentally sound technologies protect the environment, are less polluting, use all resources in a more sustainable manner, recycle more of their wastes and products, and handle residual wastes in a more acceptable manner than the technologies for which they were substitutes.

Article 4.5 of UNFCCC further specifies the obligation of developed countries that sign the contract in transferring technology to developing countries.

The developed country Parties and other developed Parties included in Annex II shall take all practicable steps to promote, facilitate and finance, as appropriate, the transfer of, or access to, environmentally sound technologies and know-how to other Parties, particularly developing country Parties, to enable them to implement the provisions of the Convention. In this process, the developed country Parties shall support the development and enhancement of endogenous capacities and technologies of the developing country Parties. Other Parties and organizations in a position to do so may also assist in facilitating the transfer of such technologies.

However, no formal legal document that provides an explicit definition of climate-friendly technology and its transfer exists. The primary reasons for this condition include scientific uncertainty and rivalry in political views. Although an explicit, unified legal concept accepted by different countries is important to solve relevant problems, the absence of such concept does not mean that no international actions are possible before this concept is established. Scientific uncertainty and clash of interests make policies and regulations with significance to environmental risk control and sustainable development highly necessary. ${ }^{6}$ Post-event remedy is often too late considering the irreversibility of climate change. Article 3.3 in UNFCCC states that

The Parties should take precautionary measures to anticipate, prevent or minimize the causes of climate change and mitigate its adverse effects. Where there

6 GILROY, J. M. Justice and nature: kantian philosophy, environmental policy and the law, 45. Washington, DC: Georgetown University Press, 2011. are threats of serious or irreversible damage, lack of full scientific certainty should not be used as a reason for postponing such measures, taking into account that policies and measures to deal with climate change should be cost-effective so as to ensure global benefits at the lowest possible cost. To achieve this, such policies and measures should take into account different socio-economic contexts, be comprehensive, cover all relevant sources, sinks and reservoirs of greenhouse gases and adaptation, and comprise all economic sectors. Efforts to address climate change may be carried out cooperatively by interested Parties.

Climate-friendly technologies have three features. Technically, climate-friendly technologies cannot be completely separated from traditional ones. The transfer of climate-friendly technologies should be conducted according to the legal norms applicable to the transfer of common manufacturing technologies. Currently, the TRIPS Agreement under the WTO framework is the major legal norm that regulates the transfer of international technology. In terms of technical purpose, climate-friendly technologies, which are distinctive from ordinary manufacturing technologies, serve the interest of the public. Therefore, the provisions on the transfer of climatefriendly technologies in international trade should be differentiated from those on the transfer of ordinary technologies. The realization of the goals of addressing climate change should be prioritized. Most climatefriendly technologies are high technologies, in which developed countries take the lead. Ownership of patents on climate-friendly technologies throughout the world indicates that developed countries have a dominant advantage. ${ }^{8}$ Furthermore, the statistics on the flow of global technologies from the Organization for Economic Cooperation and Development indicate that most trades in climate-friendly technologies occur

7 For example, many technologies are versatile. They not only belong to the traditional technical classification but also mitigate and adapt to climate change.

8 A study by the European Patent Office in 2011 shows that the top six countries in clean energy technology patents, namely, Japan, USA, Germany, Korea, the United Kingdom, and France, account for $80 \%$ of the filings for global clean-energy technologies. See United Nations Environment Programme (UNEP) Economics and Trade Branch, European Patent Office (EPO), International Centre for Trade and Sustainable Development (ICTSD), UNEP E P O. ICTSD. Patents and clean energy: bridging the gap between evidence and policy: final report, 30. Geneva, 2010. Available at: <http://www.epo.Org/clean-energy.2014-2-20>. 
in developed countries.' Therefore, the international IP system related to the transfer of climate-friendly technologies must consider the interests of the developing countries as the major recipient of technologies.

\section{B. Transfer of climate-friendly technologies and IP}

The core issue of the debate in the negotiation on technology transfer under the framework of UNFCCC is whether IP impedes the transfer of climate-friendly technology to developing countries. The basis of the controversy on IP is the unclear relationship between IP and technology transfer. Most climate-friendly technologies exist in the form of patents and are actually transferred by IP licensing via commercial channels..$^{10}$ From the legal perspective, the relationship between IP and the transfer of climate-friendly technologies can be summarized as follows. First, IP is the object in legal relationships related to the transfer of climate-friendly technologies. IP as a property right is protected by laws. Exchange of interests is possible by demarcating the boundaries between the economic interests of different parties. Thus, IP can be exchanged because of its private attribute. An international system built for IP renders such an exchange controllable. For this reason, IP is the common target considered by two parties in the transfer of climate-friendly technologies. Second, the IP system provides a static legal premise for the transfer of climate-friendly technologies. The precondition for the smooth transfer of technologies is an explicitly established property system. What the IP system provides is the recognition and protection of the intangible assets of the owners, which is the static legal premise for the trade of climate-friendly technologies. The IP system profoundly affects the entire process: from the establishment of the ownership of climate-friendly technologies to the transfer of IP. It is a "regulator" of interest balance in the transfer of climate-friendly technologies between transferors and transferees.

\section{Current situation of "Minimum Protection Standards" for international IP}

9 HAŠČIČ, I. Climate policy and technological innovation and transfer: an overview of trends and recent empirical results, 12. OECD Publishing, 2010.

10 WANG S-P; WANG C; XU Y-M. Intellectual property right and climate change, 16. Sciences Academic Press (in Chinese), 2013.
In the contemporary international system of IP rights, the TRIPS Agreement plays the leading role and has incorporated IP protection into the international trade system for the first time. Thus, the legal relationship between IP and international technology transfer is formally established. Whether in developed countries or in developing countries, the criteria for international IP protection are closely connected to the basic obligations that should be fulfilled by the members who sign international agreements on IP. The TRIPS Agreement's preamble points out that

Recognizing the underlying public policy objectives of national systems for the protection of intellectual property, including developmental and technological objectives.

However, the articles of the TRIPS Agreement do not specify the means of promoting technology transfer through technology licensing. In fact, most of the articles of the Agreement only identify the goals of technology transfer to developing countries in an advocating manner. If no new measures are implemented to establish the role of IP in technology transfer, the IP factor will either directly or indirectly impede the transfer of climate-friendly technology from developed countries to developing countries in the battle against climate change. The obligations under the TRIPS Agreement refer to the fundamental requirements for all WTO members as indicated by the minimum protection standards. ${ }^{11}$ The minimum standards for international IP cannot be easily fulfilled by developing and least-developed countries. These countries need to enhance the intensity of IP protection to fulfill international agreements. Thus, the minimum protection standards established by the international IP system represent the extension of rights and the high-level protection of rights. Article 1.1 of the TRIPS Agreement generally defines only the minimum protection standards and not the maximum ones. It states that

Members shall give effect to the provisions of this Agreement. Members may, but shall not be obliged to, implement in their law more extensive protection than is required by this Agreement, provided that such protection does not contravene the provisions of this Agreement. Members shall be free to determine the

11 TAUBMAN, A. Rethinking TRIPS AGREEMENT: 'Adequate remuneration' for non-voluntary patent licensing, 927. Journal of International Economic Law, J.I.E.L, 970, 2008. 
appropriate method of implementing the provisions of this Agreement within their own legal system and practice.

Member states should not implement IP protection below the level required by the TRIPS Agreement but have the right to execute tighter IP protection. Moreover, the rules of the minimum protection standard are worded ambiguously. The TRIPS Agreement provides explicit provisions on the terms of protection, non-discriminatory treatment of foreign residents, and enforcement measures but fails to define in detail the standard of patentability. For instance, Article 27.1 of the TRIPS Agreement specifies that any invention in any field has to meet the following conditions to obtain a patent: novelty, usefulness, and originality. However, the Agreement does not provide the details of these three conditions. Each country has the right to define the denotation and connotation of these three conditions based on specific situations. Lastly, "minimum protection standards" increase the possibility of having abusive IP. ${ }^{12}$ In developed countries, enterprises that depend highly on IP, particularly those leading in the field of climatefriendly technology, are being challenged by emerging economies. They hope that these protection criteria can function as the bottom line, based on which a higher standard for IP protection can be demanded. In this manner, these enterprises can maintain a competitive edge in technology in the long term.

In summary, the transfer of climate-friendly technologies is regulated by the international IP system. Except for a few clauses that mention the concept of "public interest," no explicit provisions indicating that "addressing climate change" is the public interest that deserves special considerations exist in this system. As a component of the one-package protocol of the WTO, the TRIPS Agreement applies to exceptional environmental terms, namely, paragraphs (b) and (g) of Article XX of the General Agreement on Tariffs and Trade (GATT). With regard to the issue of climate-friendly technology transfer, the connection between the TRIPS Agreement and exceptional environmental terms and their application ranges is difficult to identify. In particular, existing exceptional environmental terms do not directly incorporate "the measures for facilitating the diffusion of climate-

12 Includes high licensing fees, refusal to deal, market control, and the permission of the licensor to own the majority of the company's shares. friendly technologies in response to climate change." Furthermore, minimum protection standards provide considerable protection for IP in developed countries that already have an advantage. Developed countries take advantage of this condition to constantly raise the standards of IP protection. However, developing countries hardly benefit from the system. Is it true that only minimum protection standards are established by the existing international IP system?

\section{Reflection on "Minimum Protection Standards" in the international IP system}

\section{A. Is "Minimum Protection Standard" equivalent to "Unlimited Strong Protection"?}

The minimum standard for IP protection was first formulated in Article 20 of the Berne Convention and later in Article 22 of the Rome Convention. Article 19 of the Paris Convention also contains similar provisions. The TRIPS Agreement unifies and defines "minimum protection standards." The above provisions contain necessary restriction requirements that neither special protocol nor condition should not "contravene" or be a violation of the existing protocols (particularly at the end of the first sentence in Article 1.1 of the TRIPS Agreement stating that "provided that such protection does not contravene the provisions of this Agreement"). Nevertheless, the clause of "minimum protection standard" in the TRIPS Agreement continues to create controversy in terms of its connotation. One point of view is that the heading of the first sentence of this clause should be emphasized, that is, the licensor has the right to introduce additional protection within the scope of the TRIPS Agreement. ${ }^{13}$ Another point of view is that the second sentence of this clause is equally important; its potential effect is to restrict the presence of TRIPS Agreement-Plus related to the nondiscriminatory principle of the TRIPS Agreement and the enforcement of IP because many clauses of the TRIPS Agreement imply that not only the lack of IP but also the abuse of IP will impede international trade. For example, in China-Measures Affecting the Protection and Enforcement of Intellectual Property Rights, part of criminal protection indicates that the panel holds that members have the right to decide on the legal system within its domain and the appropriate methods to implement

13 GERVAIS, D. J. The TRIPSTRIPS Agreement: drafting history and analysis. 3. ed. London: Sweet \& Maxwell, 2008. 
this protocol as specified by Article 1.1 in the TRIPS Agreement. However, the panel also holds the opinion that the amount of liberty granted to the members in this respect is only slightly considerable. The panel has the right to balance. ${ }^{14}$ Thus, Article 1.1 in the TRIPS Agreement does not allow for free discretion beyond the scope of minimum protection standards. Moreover, the TRIPS Agreement does not provide a complementary explanation for such uncertainty but reserves the discretion to the panel.

The pacta sunt servanda phrase in Article 26 of the Vienna Convention on the Law of Treaties (VCLT) indicates that the requirement of Article 1.1 in the TRIPS Agreement can be paraphrased as "the national law should respect the minimum standard for IP." The purpose of delineating the scope of Article 1.1 in the TRIPS Agreement is to establish a more extensive IP system. Any form of TRIPS-Plus should not contravene the TRIPS Agreement. Setting minimum standards for IP is sufficient to realize extensive IP. Thus, TRIPS-Plus, which is higher than the TRIPS Agreement, is allowed to take effect without restrictions and without risk of being contrary to the former agreement. However, this opinion deserves a thorough discussion. Article 1.1 in the TRIPS Agreement requires the national law to respect the minimum protection standard in the Agreement, which delineates the scope of obligations that a country should bear under the framework of the Agreement. Moreover, TRIPS-Plus contains coercive provisions on IP protection. If TRIPS-Plus is acquiesced to satisfy the minimum protection standard under the TRIPS Agreement, the scope of obligations that should be fulfilled by a country under the TRIPS Agreement will be broadened contrary to the purpose of the Agreement. Thus, the minimum protection standard under the TRIPS Agreement should not be considered unlimited. A ceiling on the scope of IP must be set.

\section{B. Is TRIPS-Plus in conflict with the "Minimum Protection Standard" under the TRIPS agreement?}

In the mid-1990s, the context for reaching the agreement on the protocols for international IP shifted from WIPO and WTO to free trade agreements (FTAs). Its relationship with the IP clauses presents a

14 CHINA. Measures affecting the protection and enforcement of intellectual property rights: WT/DS362/R. Report of the Panel, 115, 116, 2009. new feature, namely, the extension of TRIPS-Plus with FTAs as the major carrier. After the implementation of the TRIPS Agreement, the international IP system featured the co-existence of several international IP protocols by the TRIPS Agreement and WIPO under a multilateral trading system. In addition, the existing non-discriminatory global trade system and the "most favored nation" treatment principle became the pillars of the WTO. Article 24 of GATT and Article 5 of the General Agreement on Trade in Services (GATS) permit FTAs with a preferential nature because developed countries that have entered the WTO want developing countries to raise the level of IP to maintain their dominance in the technology trade. The extensive existence of TRIPS-Plus combined with the insufficient number of the "most favored nation" treatment principle and national treatment clauses under the TRIPS Agreement has conflated the desire of developed countries to raise IP standards in the international norm. Accordingly, the flexible clauses and policy space under the TRIPS Agreement are nullified by the obligations in TRIPS-Plus. Thus, disputes arise over the excessive restriction on national sovereignty, particularly in the fields of climate change, public health, and knowledge acquisition.

The clauses of TRIPS Agreement do not emphasize "contravene." Article 31.1 of VCLT states that "a treaty shall be interpreted in good faith in accordance with the ordinary meaning to be given to the terms of the treaty in their context and in the light of its object and purpose." Article 7 of the TRIPS Agreement focuses on the balance of interest between the innovator and user, and Article 8 is mainly about public interest in important fields that can benefit the above judgment. Moreover, the declaration of the Doha round of the TRIPS Agreement and public health was passed in 2001. This declaration represents the consensus of WTO members in this field: "in applying the customary rules of the interpretation of public international law, each provision of the TRIPS Agreement shall be read in the light of the object and purpose of the Agreement as expressed, in particular, in its objectives and principles." This declaration can be included in the "other factors" considered in interpreting the context under Article 31.3 (a) of VCLT. Articles 7 and 8 of

15 MUSUNGU, S. F.; DUTFIELD, G. Multilateral agreements and a TRIPS AGREEMENT-plus world: the World Intellectual Property Organisation (WIPO). 26. Quaker United Nations Office (QUNO) 28, 2003. 
the TRIPS Agreement indicate that the provision in TRIPS-Plus under FTAs that allows the raising of the standards for the protection of IP by a single party is a violation of the essence of the minimum protection standard under the TRIPS Agreement. The former is only favorable to the protection of the interests of the innovator or right holder and ignores the interests of the user; it also blocks the realization of public interests, such as those in the environment and health.

The word "contravene" is explained as a type of "conflict with a right, principle, etc." in the Oxford dictionary. ${ }^{16}$ Pursuant to this definition, TRIPS-Plus and the TRIPS Agreement are in conflict with each other in terms of rights and principle. The question is, what is the "conflict" between norms? In the strictest sense, only direct incompatibility, that is, observing a necessary rule at the expense of other principles that constitutes a threat, can be regarded as true conflict. The Appellate Body of the WTO defines "conflict" in Guatemala - Definitive Anti-Dumping Measure on Grey Portland Cementfrom Mexico as a situation where adherence to the one provision leads to the violation of another. ${ }^{17}$ However, this opinion is not only about conflicting norms. The generalized understanding is that conflict also exists when the right to free choice provided by the protocol cannot be fulfilled because of the restriction and impediment imposed by other obligations in the protocol. ${ }^{18}$ Therefore, if TRIPS Agreement-Plus restricts the freedom of WTO members to implement the flexible clauses of the TRIPS Agreement, then it should be regarded as conflicting with the TRIPS Agreement.

\section{How did the panel of DSB interpret "Minimum Protection Standard"?}

In the WTO system, the Dispute Settlement Body (DSB) provides guarantee and predictability to the implementation of a multilateral trading system. To clarify the articles of the agreement, DSB provides a common, conventional interpretation as applied to national laws. Under DSB, the TRIPS Agreement

16 http://www.oxforddictionaries.com/us/definition/ american_english/contravene?q=contravene $>$.

17 The Dispute Settlement Body adopted the panel report on Guatemala: definitive anti-dumping measures on grey Portland cement from Mexico, 65 WT/DS156/R, 2000.

18 RAMANUJAN, Adarsh. Conflicts over "conflict": preventing fragmentation of international law. 1(1) 171 Trade L. \& Dev. 191, 2009. is by far the most extensive multilateral agreement concerning IP. It is subject to the following constraints: jurisdiction imposed by the appealing body, restrictive agreement of the DSB, and execution of a series of vindictive measures against non-compliance.

The cases related to the clauses of the TRIPS Agreementin DSB have given rise to many interpretations in the panel report where the "three-step test" was employed. ${ }^{19}$ The cases related to exceptional terms and restrictive clauses are the most remarkable. For instance, the panel utilized the three-step test in in Canada Patent Protection of Pharmaceutical Products to determine whether the exceptional clauses for patents apply. They dismantled the original clause into three independent conditions. Article 30 establishes three conditions, which can only be applied in combination. However, each condition is independent from one another and should be met. The requirements in Article 30 are not fulfilled when one condition is unmet. The conclusion obtained is that the clause favors the economic interests of the right holder. In fact, the "limited exception" in Article 30 is not altogether separable from the other two conditions. Nevertheless, the separation of the three conditions for the purpose of analysis is not entirely impossible. However, such separation is difficult to be implemented in practice. Article 30 provides the major international law basis for exceptional clauses for patents in international trade. Its purpose is to restrict the additional provisions imposed by WTO members on the exceptional clauses for patents. As indicated in the report by the panel, an attempt is made to dismantle Article 30 through the "three-step test." The steps are then performed one by one. Given that the condition of limited exception in the first step is found to be in conflict from the beginning, the panel directly concluded that the clause fails to fulfill the original intention and favors the right holder.

Thus, the TRIPS Agreement fails to provide an explicit provision on security and predictability related to whether it agrees with domestic exceptional clauses for IP. The reports by the panel only maintain the economic interests of the right holder through the "three-step test." WTO members are not well informed

19 WT/DS114/R. Panel report, Canada - Patent Protection of Pharmaceutical Products (Canada - Patents), 03/17/2000; WT/DS160/R. Panel Report, United States - Section 110 (5) of US Copyright Act (US - copyright), 06/15/2000; WT/DS/174R. Panel report, European Communities-Geographical Indications, 03/15/2005. 
on what to do but on what should not be done under a general context. These non-restrictive clauses assign a secondary place to the interests of the users. The only result is that TRIPS-Plus is an unlimited extension of IP at the expense of public interest. The ambiguity of the clauses and the requirement for the approval of the panel reduce the probability of a country to revise the new exceptional clauses according to the development level of the domestic economy, culture, and technology. This task is not difficult for developed countries that have a long history of establishing exceptional rights. This issue poses a real challenge for developing and least-developed countries where IP protection and enforcement have relatively low intensity. The situation is aggravated by the lack of counterbalancing by the competition law. The ambiguity of the clauses restricts developing and least-developed countries from adopting measures in the light of their needs. ${ }^{20}$

The minimum protection standard in the IP system does not necessarily mean the absence of an upper bound constraint. However, the assumption that the minimum protection standard is not equipped with an upper limit has long prevailed because of the absence of an explicit regulation on upper limit. It also gave rise to that check and balance and protection of the interests and rights of users in the international IP system are almost non-existent. Developed countries that possess an advantage in technology can actively push TRIPS-Plus forward to raise the standard for IP protection and increase the scope of protection. The room for free choice left by the TRIPS Agreement to developing countries is considerably compressed. In this situation, developing countries are unable to achieve the expected goal of improving social welfare and are severely restricted by developed countries in terms of technology innovation and transfer. Although no dispute has existed so far in direct relation to climatefriendly technology transfer owing to the flexible use of IP articles under WTO, we can obtain a general idea of the judgment by the expert panel from the case of a Canadian patented drug. However, this judgment remains unpredictable and gives rise to uncertainty in formulating policies related to climate-friendly technology transfer. Currently, some FTAs contain

20 KUR, A.; RUSE-KHAN, H. Grosse. Enough is enough: the notion of binding ceilings in international intellectual property protection, intellectual property in a fair world trade system: proposals for reform of TRIPS, 359. Edward Elgar Publishing Limited, 363, 2008. special clauses on promoting technology transfer for the purpose of tackling climate change. In particular, FTAs have clauses for promoting the development of clean energy technology, which is closely related to mitigating climate change. ${ }^{21}$ The negotiations on Trans-Pacific Partnership and Transatlantic Trade and Investment Partnership implement a high global standard for IP protection in terms of labor use and the environment. ${ }^{22}$ Thus, the use of flexible clauses in IP by developing countries to acquire climatefriendly technologies will be further restricted. Based on the assumption of the minimum protection standards in the TRIPS Agreement, Article 27.1 only provides a general provision on the three conditions for patent application and allows for discretion by the country. Such freedom can give rise to many rubbish patents or the patent thicket phenomenon for one specific patent. ${ }^{23}$ Developed countries usually draw on this clause to formulate low conditions for patent application to consolidate their technical dominance. If developing countries adopt similar conditions, the only consequence is that the number of patents filed in developed countries worldwide will increase given the technical dominance of these countries. Therefore, the entire patent system is monopolized by developed countries. Reflecting on the hazards brought about by the minimum protection standard, parties from developing countries in UNFCCC propose drawing on the flexibility clauses of the TRIPS Agreement to refine the provisions. However, WTO is yet to respond to these suggestions. As indicated in the discussion above, the efforts of developing countries to draw on the flexible clauses of the TRIPS Agreement face the huge risk of being crowded out by TRIPS-Plus. With respect to the issue of combating climate change and facilitating technology transfer, breaking the unreasonable assumption of the "minimum protection standards" for the international IP system will solve

21 BREWER, T. L. Climate change technology transfer: a new paradigm and policy agenda. 516. Climate Policy, 526, 2008.

22 USTR said the FTA can be more integrated into the global trade in intellectual property standards. Intellectual Property Protection in China. Available at: <http://www.ipr.gov.cn/ guojiiprarticle/guojiipr/guobiehj/gbhjnews/201311/1782549_1. html 2014-5-21>.

23 CORREA, C. M. Innovation and technology transfer of environmentally sound technologies: the need to engage in a substantive debate. 54. Review of European Community \& International Environmental Law, 61, 2013. 
the dilemma associated with the transfer of climatefriendly technologies.

\section{China's practice and patent laws}

The IP system is the main legal regulation that balances the interests of the transferor of climatefriendly technology and that of the transferee. The setting of the standard for IP protection reflects the value orientation in balancing the interests. The general belief in the past was that the IP system only specifies the minimum protection standard but imposes no upper limit constraint. Such misinterpretation favors the protection of the interests of the transferor at the expense of the interests of the transferee. As the largest developing country, China suffers from serious climatic disasters induced by global warming. China is currently undergoing rapid economic growth. With its huge population base and coal-dominated energy structure, China's greenhouse gas emissions will maintain an increasing trend for some time in the future. China's climate-friendly technology has developed rapidly in recent years owing to the optimization of the international environment and domestic policy support. China has reached a certain industrial scale in biomass, solar, and wind energy as well as in other technical fields. The climate-friendly technology industry in China is now booming. However, the application of climate-friendly technology in China is still in its infancy and is significantly different from that in Japan, the United States, Europe, and other developed countries and regions. Statistics show that among 110,000 patent applications for low-carbon technology for carbon capture and storage, $25 \%$ are from Japan, $20 \%$ are from the United States, and only $5 \%$ are from China. ${ }^{24}$ China possesses a large number of climate-friendly technology patents; however, the quality of these patents lags behind that in developed countries. China Human Development Report 2009/10: China and a Sustainable Future Towards a Low Carbon Economy \& Society point out that to achieve green development goals in the future, China requires the support of least 60 core technologies, most of which have not been mastered by China. ${ }^{25}$ Similar to other

24 GAO Yongyi; CHEN Kenan; SHENG Anquan. International patent analysis of low-carbon technologies. 44. Science Focus, 50, 2011.

25 UNDP. China, Remin University of China. China buman development report. 2009/10: China and a sustainable future: towards a low carbon economy and society, 46 (Zou Ji. Z.J, China. Translation and Publishing Corporation Beijing Gretchen Luchsinger, 2009. developing countries, China is a net importer of IP in the field of climate-friendly technology (particularly core technology). This condition reveals the low capacity of Chinese enterprises to research and develop low-carbon technology.

Since the negotiation on international climate, the legislation of patent protection in China has begun to comply with international standards and gradually reflects commitments to green development and environmental protection. This condition will provide a legal foundation for promoting the internationalization of China's climate-friendly technology patent protection and enhancement of industrial competitiveness. In recent years, climate-friendly technology has been guided by national macro-policies. The Outline of the Twelfth Five-Year Plan for National Economic and Social Development released in 2011 established the policy orientation of promoting green and low-carbon development and expressly set out the objectives and tasks of addressing climate change. China issued the Twelfth Five-Year National Strategic Emerging Industry Development Planning in 2012. The development of climate-friendly technologies has been included. In the same year, China also issued the Special National Science and Technology Development Scheme to Handle Climate Change during the $12^{\text {th }}$ Five-Year Plan (hereafter referred to as the Scheme); it emphasizes the reform of the economic growth pattern, the promotion of climate-friendly technology transfer, and the improvement of the IP strategy. The Scheme required a change in the existing unreasonable policy to improve the IP policy for advising and supporting Chinese businesses on low-carbon technology IP issues. The goals of the Promotion Plan for the Implementation of the National Intellectual Property Strategy in 2014 are to increase the pertinence and efficiency of IP creation, strengthen the connection between IP policies and industrial/regional policies, and promote IP in strategic emerging industries.

However, serious problems continue to exist in the current legal system for climate-friendly technology protection in China. Compared with the legislation in developed countries, the laws and regulations relating to climate-friendly technology patent and environmental protection in China are far from perfect. Laws and regulations that encourage the development of climate-friendly technology patent have not been established yet. The lag in legislative work seriously 
restricts the development of the climate-friendly technology industry. Considering that development based on climate-friendly technology patent is a new economic model, the traditional patent system still has many defects that limit the development of climate-friendly technology. Although China has established and repeatedly revised the Patent Law of the People's Republic of China (hereafter referred to as the Patent Law), no content in the Patent Law targets the development of climate-friendly technology in the aspects of patent application, examination, licensing, protection, and use. No complete and clear definition of climate-friendly technology patent has been established. Moreover, no complete system or practical provision has been established to address climate change. For example, Article 22 in the Patent Law indicates that

Any invention or utility model for which patent right may be granted must possess novelty, inventiveness, and practical applicability.

The article does not provide explicit environmental standards for patent application and cannot be utilized to effectively control and prevent non-climate-friendly technology from entering the field of green patents.

In addition, the Guidelines for Patent Examination (2010) in China provide several special requirements for patent licensing of climate-friendly technology. In its part II titled "Substantive Examination" (Chapter 4, Article 3.2.2), it regulates the "assessment of the notable progress" as follows:

When evaluating whether or not an invention represents notable progress, the examiner shall primarily consider whether or not the invention produces advantageous technical effects. Usually, an invention shall be regarded as producing advantageous technical effects and therefore representing notable progress in any of the following circumstances: (1) where, as compared with the prior art, the invention produces a better technical effect, such as quality improved, output increased, energy saving, and environmental pollution prevented or controlled. ${ }^{26}$

In its part II (Chapter 1, Article 3.1.3), the definition of "inventions/creations detrimental to public interest" is

26 State Intellectual Property Office of the People's Republic of China. Guidelines for patent examination 2010. 200. Intellectual Property Publishing House, 2010.
The expression "detrimental to public interest" means that the exploitation or use of an inventioncreation may cause detriment to the public or the society or may disrupt the normal order of the State and the society. Where the exploitation or use of an invention-creation may seriously waste energy or resources, disrupt ecological balance, or impair the health of the public, the invention-creation shall not be granted a patent right. ${ }^{27}$

Combining the two articles is in line with the goal of granting patents to technologies that combat climate change. However, in several recent revisions of the current patent law in China, the impact of and demand for low-carbon development were not specifically considered. Furthermore, promoting climate change was not directly included in the amendment scope of the patent law. The Patent Law and Patent Rules for Implementation of China currently have no clear patentability criteria to prevent high-carbon technology from obtaining patents.

Currently, China is not under direct pressure from the high protection standard in TRIPS-Plus. ${ }^{28}$ However, the raising of the protection standard has already resulted in the incompatibility between domestic climate-friendly technology innovation and actual demand for technology import. Investigations on China's renewable technology innovation and importation shows that the following problems usually exist in the practice of climate-friendly technology transfer to China: low level of public disclosure of patent information, long-term patent protection, large scope of patent protection that even extends into generic technologies, the patent holder monopolizing pricing, and restricting the ownership of rights associated with secondary inventions under the patent transfer contract. This situation indicates that balance in the IP system should be put into the schedule; otherwise, the dissemination of technological innovation would be affected. To balance the interests of the inventor and that of the public, specific reform measures should be resorted to. When it comes to formulating a reform plan, one issue to be clarified is the position of interests in the IP system. Breaking the traditional assumption

\section{Id. at $131,132$.}

28 The United States and the European Union have not yet signed an agreement with China. Thus, the Free Trade Agreements (FTAs) in which China is involved do not have problems related to the articles of TRIPS-Plus. However, China is likely to face pressure under the articles of TRIPS-Plus in contracting on FTAs later. 
would free us from the fixed pattern of thinking. Thus, we can focus more on urgent and most commonly shared interests and refrain from short-term egoism that prevents us from considering the fundamental interests of the development of human society.

China must promote the extensive application of climate-friendly technology, either introduced or developed independently, to curb the increasing trend of greenhouse gas emissions and reduce climate-related loss. For this purpose, a reflection on the Patent Law with respect to the starting point of system design is necessary to better serve the needs of climate-friendly technology development. On this basis, discarding the assumption of no upper limit constraint in protection standards and specifying a specific upper limit constraint will facilitate the introduction of foreign climate-friendly technology and the improvement of domestic and international legal environment with regard to IP. The main goal is to consolidate existing flexible articles on IP through restrictive regulations on the inside and on the outside. Hence, relevant laws will play a positive role in promoting the transfer of climate-friendly technology to developing countries. The IP system should properly balance the interests of the transferor and that of the transferee.

\section{Suggestions to Improve the Standards for IP Protection}

Patent legislation for the development of climate-friendly technology is determined by how the interaction between the patent system and the development of climate-friendly technology is considered. Climate-friendly technology development and innovation differ from that of traditional industrial technology in terms of origin. The former is grounded in the context of increasingly intensified environmental problems, whereas the latter stems from the pursuit of material life. Climate-friendly technology development is the optimization or renunciation of traditional technology. The modern patent system, aiming to fulfill the needs of climate-friendly technology development and dissemination, should start from the basic assumption about the values in adjusting this system. In this manner, the improved patent system will have an inherent mechanism that caters to the needs of low-carbon development and the fight against environmental problems. In response to climate change, encouraging climate-friendly technology innovation and dissemination should be the top priority in policy adjustment for patent systems both domestically and internationally.

Legal analysis of the "minimum protection standard" shows that the assumption that the international IP system only has "minimum standards of protection" does not hold. To popularize climatefriendly technologies and avoid the negative impact of raising the standards of IP protection by countries that have technological advantages, the inherent assumption that international IP protection only has "minimum standards" needs to be revoked. An upper limit should be set for the standard of protection on the international level and in national legislation. IP protection standards and related systems should be repositioned and improved.

The patent law for climate-friendly technology should not be adjusted following a traditional set of values but should simultaneously facilitate the protection of rights under the framework of patent law and climate-friendly technology innovation. Traditional values center on rights protection. In this case, the establishment of a patent law system and the balance in system design based on the consideration of social interests are no more than the check and balance of rights, whereas the consideration of public interests is placed in the center in the patent law that serves climate-friendly technology development. No hypothesis exists for minimum protection standards. The patent law formulated in this manner has an independent value and achieves balance between motivation for technology innovation and technology dissemination.

\section{A. International level}

To promote climate-friendly technology innovation and transfer, the exclusiveness of IP right as a private right must be balanced by the consideration of interests in the public domain. Therefore, an upper limit on the standard for IP protection should be set. Through this means, IP abuse can be prevented, and the interests of people other than the right owner will be protected (including the right of users, the right of free trade, and public interests).

First of all, the TRIPS Agreement should clarify the general provision that the public interest mentioned in this protocol includes combating climate change. The 
innovation, transfer, and spread of climate-friendly technologies should be incorporated into the general provision and public interest clause to legally support the unified international law related to the transfer of climate-friendly technologies in combating climate change. Doing so will also clarify the connection with GATT XX. The articles for promoting climate-friendly technology innovation, transfer, and dissemination should be incorporated into the general article and articles of public interests (Trips Agreement, Articles 7 and 8).

Second, a ceiling should be specified in Article 1.1. Article 1.1 of the TRIPS Agreement directly defines the minimum standards of IP protection. The first sentence indicates that IP protection in this Agreement is only required to comply with all the articles of this Agreement. The countries have no obligation to fulfill higher IP protection. However, it also affirms that all countries can carry out appropriate means allowed by the Agreement in accordance with their own circumstances, which suggests that all countries can handle issues flexibly. Flexibility may cause polarization. On the one hand, countries are provided autonomy to establish and obey protection standards that go beyond this Agreement. On the other hand, countries are provided autonomy, but no constraint is set in raising the standards of IP protection. The statement "as long as the protection does not contravene the articles of this Agreement" appears to be a restrictive provision and makes the content more ambiguous. Therefore, a clarification of this clause is necessary to set an upper limit for IP. Standards for IP protection laid down by nations that are above the present protocol cannot contravene the exceptional provisions set to serve the public's interests, such as combating climate change. IP protection standards formulated by national IP laws should meet the ceiling requirements. When the exclusive rights to IP are in conflict with the public's interests, priority should be explicitly given to the latter.

Lastly, the ceiling cannot be set by merely adjusting the clauses of the TRIPS Agreement. The assumption that IP protection standards provide only the baseline should be changed; however, this process takes time and not only involves the revision of the TRIPS Agreement by legislators but also the formulation of measures to impose the restriction on the ceiling through other means. Thus, the high standards laid down by TRIPS-
Plus also need to have a ceiling. The attitude of the DSB panel toward the standards for IP protection also needs to be changed. A preventive review mechanism for the transfer of climate-friendly technologies should be established as follows. First, a review mechanism should be set for TRIPS-Plus clauses under FTAs. According to the hypothesis of "minimum protection," the TRIPS Agreement does not place an upper limit on TRIPS-Plus' capability to raise the standards of IP protection among regions. However, the WTO has never reviewed the articles of TRIPS-Plus in the regional trade agreement. Although it was proposed to set an obligatory review mechanism for technology transfer in Hong Kong Ministerial Conference in 2003, the mechanism mainly targeted least-developed countries as mentioned in Article 66.1 in the TRIPS Agreement. In fact, such bilateral or regional trade agreements are often reviewed without allowing for the democratic input or a comprehensive assessment by the stakeholders. All of these participations should have preceded the formulation and revision of the Agreement. To protect climate-friendly technology, it was proposed in the WTO multilateral negotiations to establish a review mechanism for the terms of IP rights in bilateral or regional trade under the TRIPS Agreement. The focus is to assess the potential impact of climate-friendly technology transfer to developing countries under the articles of TRIPS-Plus. Second, in future dispute resolutions in DSB, independent assessment suggestions on whether any negative impact exists to promote climate-friendly technology development and transfer should be encouraged by environmental experts or NGOs, as friends of the court, for reference to the DSB panel. The main objective and measurement criteria are to determine whether the current interpretation of the environmental provisions is beneficial to the subsequent interpretation or at least provides an exact assessment of what can and should not be done. To increase predication auditing, if related cases occur in the future, it can play an important role in at least two aspects: (1) increasing the new legitimacy bases of the judgment and (2) the opinions of the existing panels may pass through the audit but are still biased or are apparently adverse to the interests of one party. At the least, a mechanism that can continue to improve clarity and predictability without making the problem worse should be established. 


\section{B. National level}

The hindrance to climate-friendly technology transfer brought about by the patent system is related to domestic patent protection in various countries. To fundamentally solve the conflict between climatefriendly technology transfer and patent protection, cooperation and functioning of domestic legislations are necessary. The effective implementation of international low-carbon development measures under the domestic framework of policies and legislations will in turn strengthens the confidence of the international society in climate-friendly technology development. This is a virtuous circle for global climate governance. Therefore, the adaptation ability of domestic policies should be considered in designing a plan for coordinating international conventions. Protecting IP rights of climate-friendly technology by passing laws can contribute to the development and dissemination of climate-friendly technology and will ultimately enhance China's industrial competitiveness. This is the only means for China to develop climatefriendly technology under the influence of global integration. From the domestic point of view, the values of the related IP protection system, on the one hand, should be consistent with the commitments to the protection of IP rights as China enters WTO; on the other hand, they should not blindly follow the high standards of IP protection. China should improve the domestic environment of the IP system to ensure the independent innovation of climate-friendly technology and the introduction of advanced technology from other countries. Specifically, the Patent Law in China directly relating to the transfer of climate-friendly technology provides the following recommendations.

First, the patent system should reflect the urgent demand in the fight against climate change. To control climate change and enhance China's ability to introduce and develop climate-friendly technologies, China's patent legislation should incorporate the ideas of sustainable development, environmental protection, and climate change response into the scope of public interests. Thus, support can be provided in terms of basic principles and values for incorporating the regulations on the transfer of climate-friendly technologies into the flexible term reserved for the benefit of public interests.

Second, the setting of an upper limit on the standards for IP protection does not exclude raising the minimum standard for IP protection. The purpose of limit setting is to safeguard the policy space of flexible terms that all countries can utilize for the sake of public interests. If countries can use flexible terms according to their respective actual situations to promote technological innovation and dissemination, it will conform to the intended goal of setting the upper limit for the standards of IP protection. Article 27.1 of the TRIPS Agreement leaves room for discretion on patents granted in each country. Given that the issue of climate change response has not been included in the amendment scope of patent law, China's Patent Law and Patent Rules for Implementation currently have no clear patentability criteria to prevent high-carbon technology from obtaining patents. As a result, many highcarbon technologies have acquired patent protection. Backward production capacity and technologies that should be eliminated have been legitimized. Assertion must be made that in determining the creativity and practicality of an invention, an invention shall not be patentable on any account if it does not comply with the environmental protection criteria provided by the Patent Law. Another proposal is to introduce "climatefriendliness" requirements into the Patent Law and the Patent Law Rules for Implementation as one of the criteria to assess patentability. Thus, China's Patent Law would mainly protect technologies that are higher in quality, more advanced, and more helpful in addressing climate change. Furthermore, it would prevent the phenomenon of "patent thickets" in the development of climate-friendly technologies.

\section{Conclusion}

In conclusion, setting a ceiling for the IP system is necessary but is not equivalent to denying that protection above the minimum protection level is unreasonable. Nevertheless, the prerequisite, at the least, is that the public interest of combating climate change can be realized with priority under the flexible clauses for IP protection. The setting of the ceiling remains risky. Thus, one-size-fits-all provisions should be avoided in international institutions. Advanced legislative techniques should be employed at both international and national scales. A systematic arrangement is required in terms of institutional value and content. The international controversy that "the IP system impedes the transfer of climate-friendly technologies" triggers a more thorough reflection on the international IP system. The presumption that 
the international IP system only provides minimum protection standards should be eliminated. Doing so is beneficial for establishing a more reasonable legal system for the transfer of climate-friendly technologies. Future studies should focus on whether international and national legislations, including the IP system, facilitate the transfer of climate-friendly technologies to developing countries. Another issue is how to establish and improve legislations for this purpose. The IP system is currently undergoing dynamic development, and the balance of interests involved in it also needs to be viewed from a dynamic perspective. The key to striking balance in the field of climate-friendly technology is to determine the baseline of the new balance. In the context of the common environmental problem for the entire human race, this baseline is different from that intended to motivate innovation. As one of the goals of the establishment of an IP system, climate-friendly technology should be given the highest priority in the fight against climate change. 


\section{Bibliography}

AGENDA 21. United Nations Conference on Environment and Development. Rio de Janeiro, 1992.

AGREEMENT on Trade-Related Aspects of Intellectual Property Rights (TRIPS). 1994.

BREWER, T. L. Climate change technology transfer: a new paradigm and policy agenda. 516. Climate Policy, 526, 2008.

CHINA. Measures affecting the protection and enforcement of intellectual property rights; WT/DS362/R, Report of the Panel. 115,116. 2009.

CHINA. Patent Law of The People's Republic of China. 2010.

CIE, The Coalition for Innovation, Employment and Development. Joint resolution of BUSINESSEUROPE, IIPPF and the Global Intellectual Property Center on Climate Change, Technology and Intellectual Property Rights, 2009. Available at: <http://www.thecied.org/ files /2010/10/FinalJointGreenTechnologiesClimateCh angeStatementSept2809.pdf>.

CORREA, C. M. Innovation and technology transfer of environmentally sound technologies: the need to engage in a substantive debate. 54. Review of European Community \& International Environmental Law, 61, 2013.

GAO Yongyi; CHEN Kenan; SHENG Anquan. International patent analysis of low-carbon technologies. 44. Science Focus, 50, 2011.

GERVAIS, D. J. The TRIPSTRIPS Agreement: drafting history and analysis. 3. ed. London: Sweet \& Maxwell, 2008.

GILROY, J. M. Justice and nature: kantian philosophy, environmental policy and the law, 45. Washington, DC: Georgetown University Press, 2011.

GUATEMALA. Definitive anti-dumping measures on grey Portland cement from Mexico; 65 WT/DS156/R, Report of the Panel. 65. 2000.

HAŠČǏ̌, I. Climate policy and technological innovation and transfer: an overview of trends and recent empirical results. 12 OECD Publishing, 2010.

INTELLECTUAL PROPERTY PROTECTION IN CHINA. USTR said the FTA can be more integrated into the global trade in intellectual property standards. Available at:

KUR, A.; RUSE-KHAN, H. Grosse. Enough is enough: the notion of binding ceilings in international intellectual property protection. Intellectual property in a fair world trade system: proposals for reform of TRIPS, 359. Edward Elgar Publishing Limited. 363, 2008.

MUSUNGU, S. F.; DUTFIELD, G. Multilateral Agreements and a TRIPS AGREEMENT-plus world: the World Intellectual Property Organisation (WIPO). 26. Quaker United Nations Office (QUNO). 28. 2003.

RAMANUJAN, Adarsh. Conflicts over "conflict": preventing fragmentation of international law. 1(1) 171. Trade L. \& Dev., 191, 2009.

RUSE-KHAN, H. G. Time for a paradigm shift: exploring maximum standards in international intellectual property protection, 1 . Trade L. \& Dev., 56, 2009.

STATE INTELLECTUAL PROPERTY OFFICE OF THE PEOPLE'S REPUBLIC OF CHINA. Guidelines for Patent Examination 2010. 200. Intellectual Property Publishing House, 2010.

TAUBMAN,A. Rethinking TRIPS agreement: 'adequate remuneration' for non-voluntary patent licensing, 927. Journal of International Economic Law, J.I.E.L, 970, 2008.

TWN, Third Word Network. UNFCCC technology committee debates IPR issue, 2013. Available at: <http:// www.twnside.org.sg/title2/climate/info.service/2013/ climate130705.htm>.

UNDP. China, Remin University of China. China Human Development Report. 2009/10: China and a sustainable future: towards a low carbon economy and society. 46. Beijing: Zou Ji. Z.J, China Translation and Publishing Corporation; Gretchen Luchsinger, 2009.

\section{UNITED NATIONS ENVIRONMENT}

PROGRAMME (UNEP); Economics and Trade Branch; European PATENT OFFICE (EPO); International Centre for Trade and Sustainable Development (ICTSD). Patents and clean energy: bridging the gap between evidence and policy: final report. Geneva, 2010.

UNITED NATIONS. Framework Convention on Climate Change, 1992.

WANG S-P; WANG C; XU Y-M. Intellectual property right and climate change, 16. Sciences Academic Press (in Chinese), 2013.

<http://www.ipr.gov.cn/guojiiprarticle/guojiipr/ guobiehj/gbhjnews/201311/1782549_1.html 2014-5-21>. 
Para publicar na Revista de Direito Internacional, acesse o endereço eletrônico www.rdi.uniceub.br ou www.brazilianjournal.org.

Observe as normas de publicação, para facilitar e agilizar o trabalho de edição. 